\title{
Nuclear Architecture in the Medulla Oblongata of the Adult African Giant Pouched Rat (Cricetomys gambianus, Waterhouse - 1840)
}

\author{
Arquitectura Nuclear en la Médula Oblonga de la Rata Gigante de \\ Carillos Africana Adulta (Cricetomys gambianus, Waterhouse - 1840)
}

"Ibe, C. S; "Onyeanusi, B. I.; "Hambolu, J. O. \& **Ayo, J. O.

IBE, C. S.; ONYEANUSI, B. I.; HAMBOLU, J. O. \& AYO, J. O. Nuclear architecture in the medulla oblongata of the adult African giant pouched rat (Cricetomys gambianus, Waterhouse - 1840). Int. J. Morphol., 29(2):382-388, 2011.

SUMMARY: The architecture of cranial and non-cranial nerve nuclei in the medulla oblongata of the African giant pouched rat was studied by means of light microscopy. Serial sections of the medulla oblongata, in coronal and saggital planes, were stained with the cresyl fast violet and silver stains, respectively. Sections in the saggital plane were used as a guide, while coronal sections were used to identify the nuclei in the rostrocaudal extent of the medulla oblongata. With the obex serving as the landmark, nuclei rostral and caudal to the obex were delineated. Cranial nerve nuclei whose architecture were defined were the motor nucleus of hypoglossal nerve, motor nucleus of vagus nerve, cochlear nucleus, vestibular nucleus and nucleus ambiguus, while non-cranial nerve nuclei identified were the olivary nucleus, solitary tract nucleus, gracile nucleus, cuneate nucleus, spinal nucleus of trigeminal nerve, motor nucleus of corpus trapezoideum, lateral nucleus of reticular formation and gigantocellular nucleus. The olivary nucleus was the most prominent nucleus, while the solitary tract nucleus was faint, and thus, less developed. The rostrocaudal extent of the solitary tract nucleus, olivary nucleus and motor nucleus of hypoglossal nerve were $3.81 \mathrm{~mm}, 2.36 \mathrm{~mm}$ and $3.50 \mathrm{~mm}$ in length, respectively. The prominent olivary nucleus, pyramidal tract and vestibular nucleus are indicative of a good motor coordination and balance, while the poorly developed solitary tract nucleus points to less efficient autonomic functions in this rodent. The present study will serve as a lead for future neuro-behavioural studies necessary for an effective domestication and adaptation of the African giant pouched rat.

KEY WORDS: Cranial nerve nuclei; Non-cranial nerve nuclei; Medulla oblongata; Obex.

\section{INTRODUCTION}

Several cranial and non-cranial nerve nuclei have been described in the medulla oblongata. The nuclei reside in the gray matter of the medulla oblongata and function in the regulation of vital body processes. For example, the regulatory centres of cardiovascular and respiratory functions are located in the medullary tegmentum which consists of the solitary tract nucleus and dorsal vagal nucleus (Allen \& Cechetto, 1992; Nolte, 2002). The white matter of the medulla oblongata contains all ascending and descending fibres that communicate with the brain and spinal cord (Paxinos, 2004).

African giant pouched rats are considered delicacies by poor and rich Africans alike. However, due primarily to reduced habitat and dense human population, the rodents are no longer present in West Africa in sufficient numbers to satisfy human demand (Fiedler, 1990). Sequel to this, the Nigerian Wildlife Conservation Committee encouraged their domestication and breeding. A good knowledge of the unique behavioural traits exhibited by the African giant pouched rat is necessary for effecting domestication. Hence, the present study was aimed at elucidating the nuclear architecture in the medulla oblongata of the rat with the view of providing explanations to some of their behavioural traits. Furthermore, the present study will serve as a guide for electrophysiological investigations of cranial and non-cranial nerve nuclei in the medulla oblongata of the African giant pouched rat. Although the Wistar rat is a rodent model for neurophysiological research, electrophysiological studies may be less tedious with the African giant pouched rat due to the relative large body size with resultant large size of their medullary nuclei.

\footnotetext{
* Department of Veterinary Anatomy, Ahmadu Bello University, Zaria, Nigeria.

** Department of Veterinary Physiology and Pharmacology, Ahmadu Bello University, Zaria, Nigeria.
} 


\section{MATERIAL AND METHOD}

Experimental animals. Twenty nine captive, clinically healthy, adult African giant pouched rats, weighing between $1.20 \mathrm{Kg}$ and $1.50 \mathrm{Kg}$ were used for the study. The animals were captured live from the wild in Kaduna State, Nigeria. They were acclimatized for 1 month in standard laboratory cages in the animal pen of the Department of VeterinaryAnatomy, Ahmadu Bello University, Zaria, Nigeria. Feed and drinking water were made available $a d$ libitum. They were physically examined during the pre-experimental period and only clinically healthy ones were utilized.

Brain extraction and separation of the medulla oblongata. The heads were perfused with physiologic saline solution through the common carotid artery immediately after slaughter to flush the brain free of blood. This procedure was immediately followed by perfusion of the brain with $10 \%$ phosphate-buffered formalin. Thereafter, the brains were extracted by the method of Ramaswamy (1978).

To isolate the medulla oblongata from the rest of the brain, the cerebrum was firstly removed viz: the two cerebral hemispheres were gently pulled apart at the occipital pole to expose the corpus callosum. The entire corpus callosum together with the septum pellucidum and the body and rostral commissure of the fornix were severed in the midline. This completely separated the cerebrum from the brainstem and cerebellum. In order to separate the cerebellum from the brainstem, the floculli of the cerebellum were manually raised to expose the cerebellar peduncles. These peduncles were then severed on both sides starting with the laterally located brachium restiformis, followed by the middle brachium pontis and then the brachium conjuctivum. Finally, the brainstem was freed from the arachnoidea and cranial nerves by simple trimming. Using a scalpel blade, an incision made at the pontomedullary junction isolated the medulla oblongata from the brainstem. The mean length of the medulla oblongata obtained with a vernier calliper (MG6001DC, General Tools and Instruments Company, New York; sensitivity: $0.01 \mathrm{~mm})$ was $10.200 \mathrm{~mm}( \pm 0.327)$. They were thereafter immersed in fresh $10 \%$ phosphatebuffered formalin for 1 week before embedding.

Preparation of slides and staining procedure. The samples were washed in tap water and kept therein for 24 hours; and thereafter dehydrated in a series of ascending concentration of alcohol, cleared in xylene, infiltrated with molten paraffin wax (BDH Chemicals Ltd. Poole, England) at $60^{\circ} \mathrm{C}$, blocked in paraffin according to standard procedures (Kiernan, 1990) and labelled.
Serial coronal and sagittal sections were cut at a nominal thickness of $10 \mu \mathrm{m}$ through the entire extent of the medulla oblongata using Jung rotary microtome (Model 42339, Berlin, Germany). The first 1-3 sections through a given block to show medullary tissue were mounted on a glass slide and numbered 1, with all subsequent sections being numbered sequentially. The sections mounted on glass slides were then dried, deparaffinised, stained and coverslipped using DPX as the mountant. Specifically, coronal sections were stained using the cresyl fast violet stain for Nissl substance and nerve nuclei (Drury, 1967) while sagittal sections were stained using the silver stain for nerve cells and fibres (Hirano \& Zimmerman, 1962). Images of sectioned rat brainstem from the Wisconsin comparative brain collection (Welker et al. 1998) and from Paxinos and Watson's stereotaxic atlas (Paxinos \& Watson, 1998) were used as references for histological landmarks and nuclear organization. Images of these nuclei were photographed with a digital eyepiece (Scopetek® DCM500, Resolution: 5M pixels) attached to a light microscope (OLYMPUS ${ }^{\circledR}-$ XSZ107BN, Hamburg, Germany). The length of each nucleus was calculated by multiplying the number of sections in which the particular nucleus was identified with the section thickness (Arora \& Prakash, 2006). Nomina Anatomica Veterinaria (2005) was used for nomenclature.

\section{RESULTS}

Under the light microscope, it was observed that there were consistent and similar nuclear characteristics in all animals and between sexes. The nuclei were paired, each located in opposite side of the medulla oblongata.

Cranial nerve nuclei: the following nuclei of cranial nerves were studied:

Cochlear nucleus: The cochlear nucleus was well represented in the histologic section that was $2.1 \mathrm{~mm}$ rostral to the obex (Fig. 1D). It was composed of dorsal and ventral subnuclei. The dorsal cochlear nucleus was located on the dorsolateral portion of the medulla oblongata, dorsal to the spinal nucleus of trigeminal nerve and lateral to the restiform body.

Vestibular nucleus: This was separated from the dorsal cochlear nucleus by the restiform body (Fig. 1B). It was located on the dorsal surface of the medulla oblongata, lateral to the midline. It was a large nucleus with prominent neurones. 
Nucleus ambiguus: This nucleus was found dorsal to the lateral reticular nucleus throughout its extent (Fig. 2M). However, more rostral, the nucleus migrated ventrally. It was medial to the spinal trigeminal nucleus. It was a small nucleus in the African giant pouched rat. Neurones of this nucleus were, however, very prominent.

Motor nucleus of vagus nerve: The rostral portion of this nucleus was well represented in the histologic section that was $0.75 \mathrm{~mm}$ caudal to the obex (Fig. 2A). It was located on the dorsal surface of the closed medulla oblongata. It laid dorsolateral to the motor nucleus of hypoglossal nerve as it approached the pyramidal decussation (Fig. 3J). It was quadrilateral in outline. It was longer and wider than the hypoglossal nucleus in their rostro-caudal extent.

Motor nucleus of hypoglossal nerve: This nucleus had an oval shape, laid medial to the motor nucleus of the vagus nerve and lateral to the reticular formation (Fig. 3I). The most rostral extent was located in the floor of fourth ventricle and the caudal portion was observed at the level of pyramidal decussation. The caudal portion was situated on the ventrolateral aspect of the central canal. It measured $3.50 \mathrm{~mm}$ in its rostrocaudal extent. The motor nucleus of hypoglossal nerve was subdivided into ventral and dorsal subnuclei. The nucleus was smaller in size than the adjacent motor nucleus of vagus nerve.

Non-cranial nerve nuclei: the following non-cranial nerve nuclei were studied:

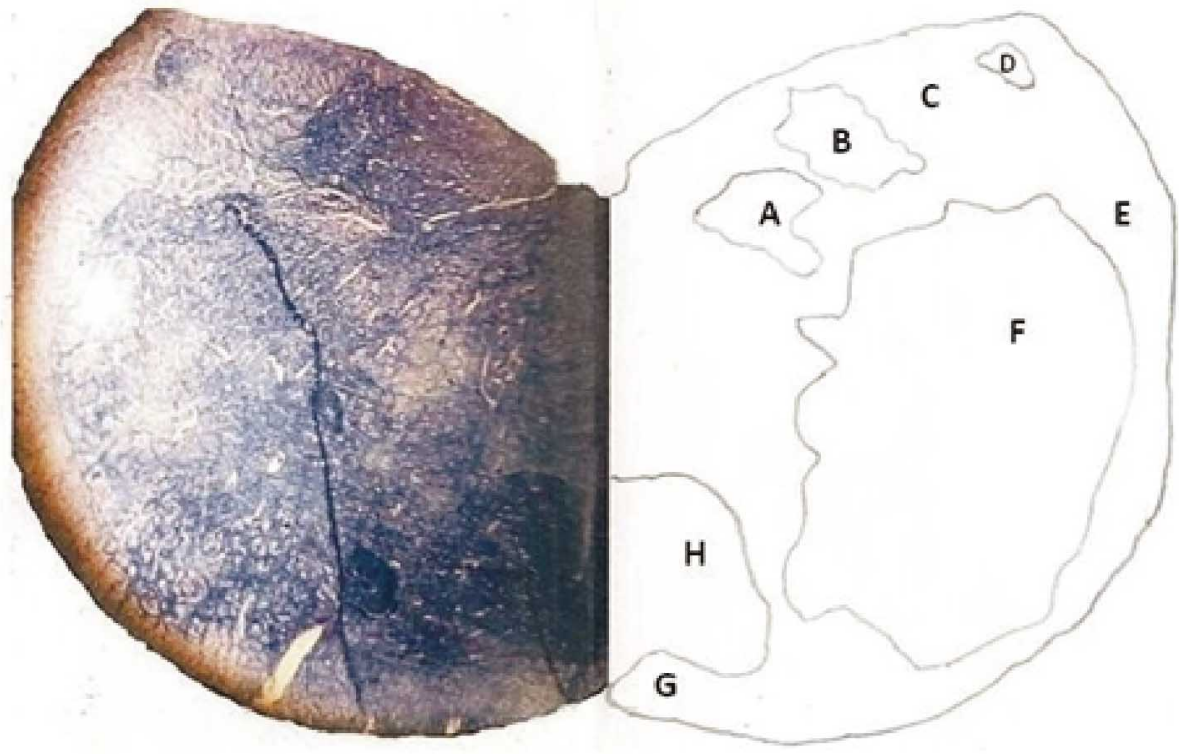

Fig. 1. Coronal section of the medulla oblongata at $2.1 \mathrm{~mm}$ rostral to the obex. A: Nucleus praepositus hypoglossi. B: Nucleus vestibularis. C: Restiform body. D: Nucleus cochlearis. E: Tractus spinalis $n$. trigemini. F: Nucleus spinalis $n$. trigemini. G: Tractus pyramidalis. H: Nuclei raphe. (Cresyl fast violet, $\mathrm{x} 40$ ).

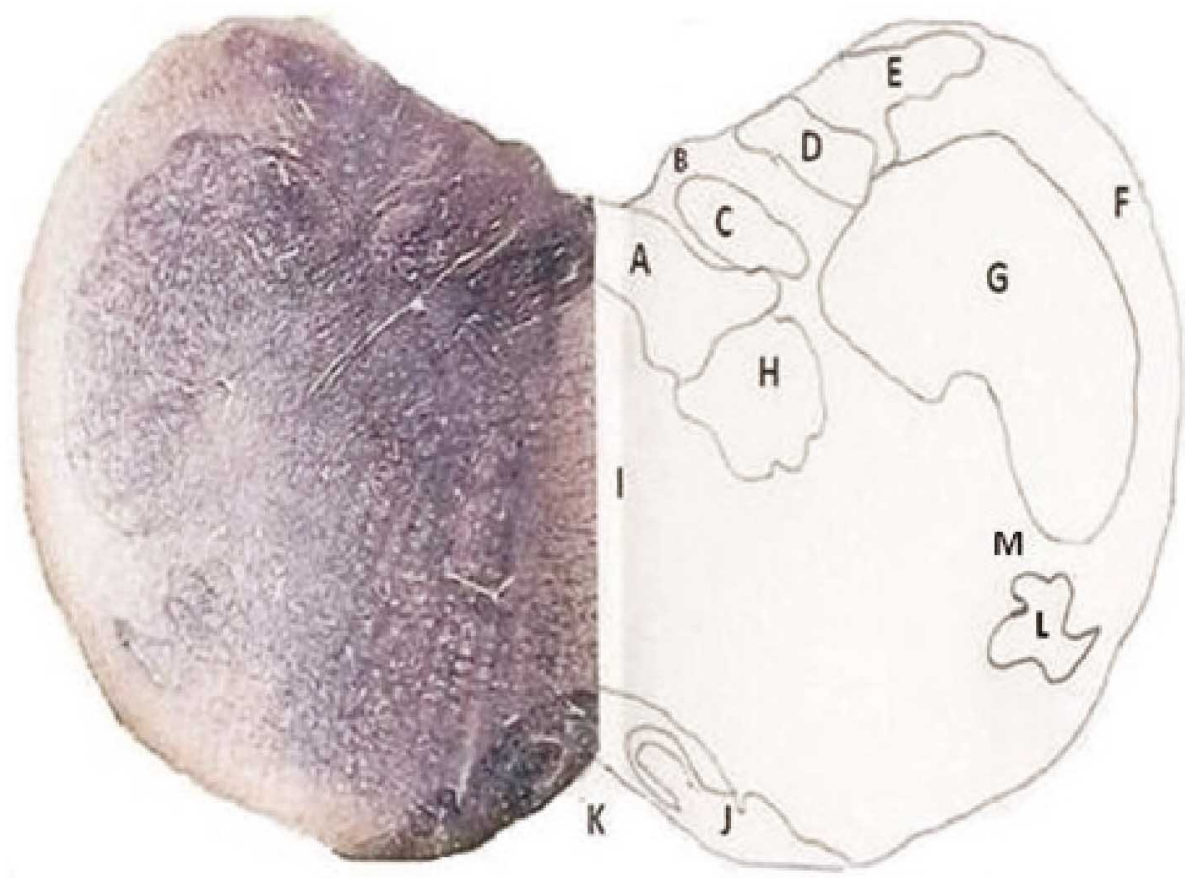

Fig. 2. Coronal section of the medulla oblongata at $0.75 \mathrm{~mm}$ caudal to obex. A: Nucleus motorius n. vagi. B: area postrema. C: Nucleus tractus solitarii. D: Nucleus gracilis. E: Nucleus cuneatus. F: Tractus spinalis n. trigemini. G: Nucleus spinalis n. trigemini. H: Nucleus dorsalis corporis trapezoidei. I: Reticular alba. J: Nucleus olivaris. K: Tractus pyramidalis. L: Nucleus reticularis lateralis. M: Nucleus ambiguus. (Cresyl fast violet, x 40).

Olivary nucleus: On a coronal section of the medulla oblongata, at $0.75 \mathrm{~mm}$ caudal to the obex, the olivary nucleus was located on the ventral surface, just dorsal to the 


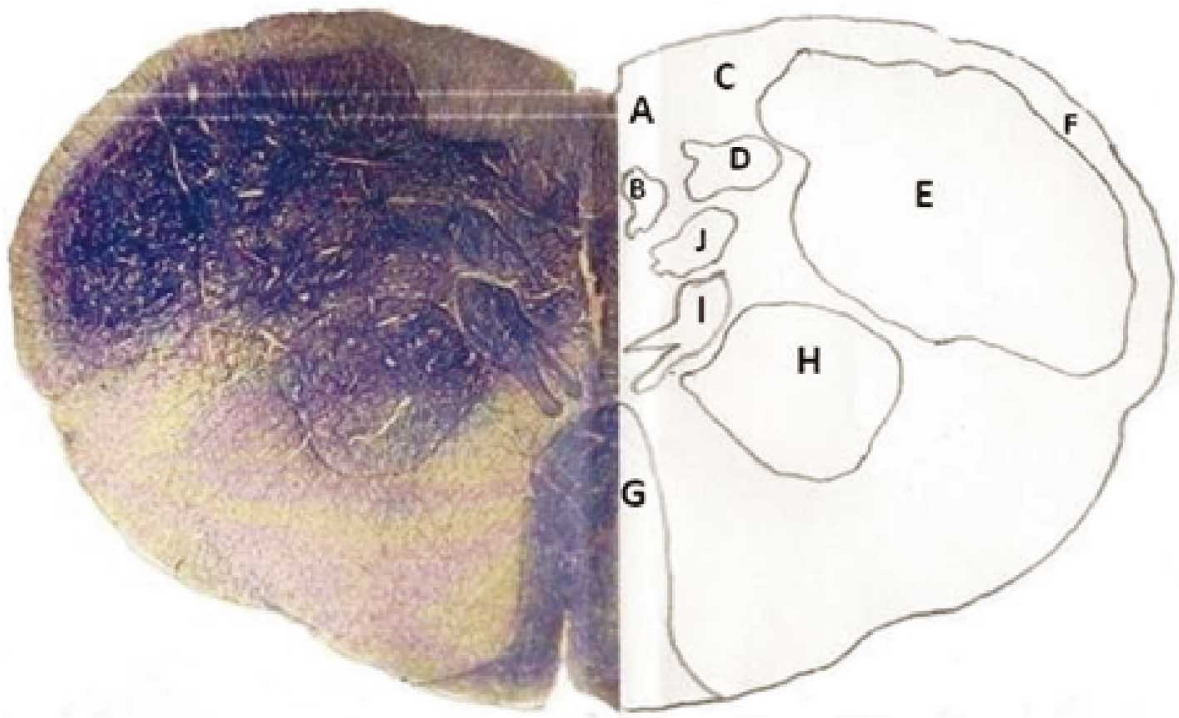

Fig. 3. Coronal section of the medulla oblongata at level of pyramidal decussation. A: Tractus gracilis. B: Nucleus gracilis. C: Tractus cuneatus. D: Nucleus cuneatus. E: Nucleus spinalis $n$. trigemini. F: Tractus spinalis $n$. trigemini. G: Decussatio pyramidum. $\mathrm{H}$ : Nucleus gigantocellulartis. I: Nucleus motorius n. hypoglossi. $\mathrm{J}$ : Nucleus motorius n. vagi. (Cresyl fast violet, $\mathrm{x} 40$ ). pyramidal tract on each half of the closed medulla oblongata (Fig. 2J). It had an undulating appearance, and was very distinct. However, it was not visible throughout the rostrocaudal extent of the medulla oblongata. It was 2.36 $\mathrm{mm}$ in length, extending from $1.1 \mathrm{~mm}$ rostral to the obex to $1.26 \mathrm{~mm}$ caudal to the obex. The pyramidal tract was evident ventral to the olivary nucleus in histologic sections of the caudal medulla oblongata (Fig. 2K). The tract was made of motor axons; thus, it constituted the white matter of the medulla oblongata.

Solitary tract nucleus: It was an elongated nucleus located on the dorsomedial medulla oblongata (Fig. 2C). It extended rostrocaudally from the obex to a point close to pyramidal decussation. The rostrocaudal extent of the solitary tract nucleus was $3.81 \mathrm{~mm}$ in length. The rostral portion of this nucleus was bounded dorsolaterally by the gracile nucleus, dorsomedially by the area postrema and ventrally by the solitary tract. The nucleus was faint with only two subnuclei.

Gracile and cuneate nuclei: On a coronal section, these nuclei were well represented in the histologic section that was 0.75 mm caudal to the obex (Fig. 2D and 2E). The gracile nucleus was quadrilateral in outline. It laid on the dorsal border of the medulla oblongata, medial to the cuneate nucleus and lateral to the solitary tract nucleus. The cuneate nucleus was $3.10 \mathrm{~mm}$ in length, and was better developed than the gracile nucleus.

Spinal nucleus of trigeminal nerve: On a coronal view (Figs. $1 \mathrm{~F}, 2 \mathrm{G} ; 3 \mathrm{E})$, this was a large bean-shaped nucleus on the lateral medulla oblongata. In the section $0.75 \mathrm{~mm}$ caudal to the obex (Fig. 2G), it was bounded dorsally by the lateral cuneate nucleus, dorsomedially by the medial cuneate nucleus and laterally by the spinal trigeminal tract. It extended throughout the lateral surface of the entire medulla oblongata.

Dorsal nucleus of corpus trapezoideum: This was an elongated nucleus. On the histologic section that was 0.75 mm caudal to the obex, the dorsal nucleus of trapezoid body was well represented on the dorsal surface of the closed medulla oblongata (Fig. $2 \mathrm{H}$ ). It was medial to the spinal nucleus of trigeminal nerve and ventral to the motor nucleus of vagus nerve.

Lateral nucleus of reticular formation: Reticular formation in the medulla oblongata was characterised by the axon-laden reticular alba and the reticular grisea. The reticular grisea was delineated by the lateral nucleus of reticular formation (Fig. 2L). The reticular alba was very prominent on either side of the midline (Fig. 2I). The rostral extent of the lateral nucleus of reticular formation was located on the ventrolateral surface of the closed medulla oblongata (Fig. $2 \mathrm{~L}$ ). It lied ventral to the nucleus ambiguus, ventromedial to the spinal trigeminal nucleus and lateral to the olivary nucleus. It was made of dorsal and ventral subnuclei.

\section{DISCUSSION}

According to Adogwa et al. (1990), a nucleus is well developed when the extent of the nucleus is large. Also, a well developed nucleus will have prominent Nissl substances in their cytoplasm. Since the cresyl fast stain has affinity for Nissl, such developed nucleus will be very prominent on 
histological section with the cresyl fast violet stain. Similarly, a poorly developed nucleus will fail to pick up the stain properly and, thus, appear faint on histologic section. Based on this principle, the olivary nucleus and motor nucleus of trigeminal nerve, as observed in the study, were among the most developed nuclei in the medulla oblongata of the adult African giant pouched rat, while the solitary tract nucleus was poorly developed.

Sricharoenvej et al. (2008) proposed that since neurones of the olivary nucleus project to the contralateral cerebellum and are linked with the vestibular nuclei, the olivary nucleus may be involved in motor coordination and balance. The authors also reported a poorly developed olivary nucleus in the flying fox and attributed this to their normal behaviour of flying and poor motor coordination. The well developed olivary nucleus in the present study contributes to the good motor coordination and balance in the African giant pouched rat.

The solitary tract nucleus was very faint and thus less developed. This also implies that the autonomic nervous system involved in digestive, cardiovascular and respiratory related activities may be less efficient in the African giant pouched rat as is obtainable in primates, in which Noback \& Gross (1959) reported that the solitary tract nucleus is developed with numerous subnuclei.

The motor nucleus of hypoglossal nerve observed in the study was small in size, relative to the adjacent motor nucleus of the vagus nerve. Also, the nucleus was devoid of the numerous subdivisions like that of the Albino rat as reported by Arora \& Prakash, who emphasized that the hypoglossal nucleus of Albino rats was a well-developed nucleus with a ventral, dorsal and central subnuclei throughout its length. They also reported that the dorsal and ventral subnuclei were further subdivided into ventromedial, ventrolateral, dorsomedial and dorsolateral subdivisions. Krammer et al. observed the dorsal subnucleus only in the dorsal 2/3rd, ventrolateral sub-nucleus in the caudal 1/3rd and ventro-medial subnucleus throughout the length of the hypoglossal nucleus of rats. In the present study, only the ventral and dorsal subnuclei were distinct. This is in consonance with the report of Guo et al. (1996) in rats. Krammer et al., using horseradish peroxidase technique, reported that the rostrocaudal length of hypoglossal nucleus in the rat was $3.5 \mathrm{~mm}$. Arora \& Prakash, using histological procedure, stained with cresyl violet, reported an average rostrocaudal length of $2.7 \mathrm{~mm}$ in hypoglossal nucleus of the Wistar rat. A length of $3.1 \mathrm{~mm}$ was recorded in the present study for the African giant pouched rat.

The Nucleus ambiguus has been grouped as a cranial nerve nucleus in the present study, based on literature reports (Paxinos, 2004; Nomina Anatomica Veterinaria, 2005) that the contents of the nucleus include motor nucleus of glossopharyngeal nerve, motor nucleus of vagus nerve and motor nucleus of accessory nerve. These three nuclei are cranial nerve nuclei. In this study, nucleus ambiguus was located in the rostral portion of the medulla oblongata, on the ventrolateral surface. It disappeared in the histologic sections representing the caudal portion of the medulla oblongata. In the sections, the motor nucleus of the vagus nerve was evident. This explains that the motor nucleus of the vagus may be a component of the nucleus ambiguus, as evident in the caudal medulla oblongata. Bieger \& Hopkins (1987) noted that the inconsistent use of terminology regarding the nucleus ambiguus is due to the fact that the nucleus lacks the structural and functional homogeneity implicit in the classical neuroanatomical concept of a nucleus.

The cuneate and gracile nuclei relay impulses of the general somatic afferents. They receive the ascending input from the primary afferent fibres that originate from the dorsal root ganglion neurones supplying the limbs (Lue et al. 1993), and then project to the contralateral ventral caudolateral nucleus of the thalamus through the medial lemniscus (Lue et al., 1996). The gracile nucleus receives impulses from axons of the ipsilateral hind limb, while the cuneate nucleus receives impulses from axons of the forelimb (Sturrock, 1989). The result of the present study showed that the cuneate nucleus of the African giant pouched rat was more prominent than the gracile nucleus. This implies that the afferent fibres of the fore-limbs of the African giant pouched rat may be more numerous than those of the hindlimbs. Ariens-Kapper et al. (1960) conducted a general study of cranial nerve nuclei in man and animals and reported that the cuneate and gracile nuclei are developed in carnivores and primates.

The present study also revealed developed pyramidal tracts. The tracts contributed to the large pyramids with a mean length and width of $7.950 \mathrm{~mm}$ and $1.482 \mathrm{~mm}$, respectively (Ibe et al., 2010). Breazile et al. (1967) reported poorly developed pyramidal tracts in ungulates. Sricharoenvej et al. (2008) demonstrated that the pyramidal tract of bat is small. Majewska-Michaska (1997) also reported small pyramidal tract in guinea pigs. This tract is quite large in humans (Carpenter, 1991). The pyramidal tract is the somatic motor column, relaying motor impulses from higher brain centres to the somatic motor system, thus, facilitating the activity of flexor motor neurones (King, 1993; Jennings, 2004). Since this tract is involved in motor control of the distal limbs leading to fine voluntary skills, it is possible that the African giant pouched rat can perform fine voluntary skills better than guinea pigs, bats and ungulates. 
The ability of the rat to stand only on its hindlimbs when fighting is a fine voluntary skill, which artiodactyls do not posses. The African giant pouched rats are also good runners, during which their long tails serve for balance as the tailends stand up vertically.

The present study has provided, for the first time, an insight into the arrangement and relative development of medullary nuclei in the adult African giant pouched rat. The study has also provided a functional-anatomic correlation of the nuclei. Neuroanatomical data obtained in the present study are vital for future neurobehavioural studies geared towards effective adaptation of the rodent.

ACKNOWLEDGEMENTS: The authors wish to acknowledge the leading contributions of Professor S. A. Ojo and Dr. S. O. Salami of the Department of Veterinary Anatomy, Ahmadu Bello University, Zaria, Nigeria. We also appreciate the efforts of Mr. Adetiba Bamidele of the Histology Unit, Department of Human Anatomy, in preparing the slides.

IBE, C. S.; ONYEANUSI, B. I.; HAMBOLU, J. O. \& AYO, J. O. Arquitectura nuclear en la médula oblonga de la rata gigante de carillos africana adulta (Cricetomys gambianus, Waterhouse - 1840). Int. J. Morphol., 29(2):382-388, 2011.

RESUMEN: Se estudió mediante microscopía de luz la arquitectura de los núcleos de los nervios craneales y no craneales en la médula oblonga de la rata gigante de carillos africana. Secciones seriales de la médula oblonga, en los planos coronal y sagital, se tiñeron con violeta de cresil rápida y tinción de plata, respectivamente. Como guías se utilizaron secciones en el plano sagital, mientras que, secciones coronales se utilizaron para identificar los núcleos en la extensión rostrocaudal de la médula oblonga. Fueron delineados, con el óbex que actúa como punto de referencia, los núcleos rostral y caudal a éste. Los núcleos de los nervios craneales cuya arquitectura se definió fueron los núcleos: motor del nervio hipogloso, motor del nervio vago, coclear, vestibulares y ambiguo, mientras que los núcleos de los nervios craneales no identificados fueron: olivar, del tracto solitario, grácil, cuneiforme, espinal del nervio trigémino, motor del cuerpo trapezoide, lateral de la formación reticular y gigantocelular. El núcleo olivar fue el más importante, mientras que el núcleo del tracto solitario fue tenue, y por lo tanto, menos desarrollado. Las longitud rostrocaudal de los núcleos del tracto solitario, olivar y motor del nervio hipogloso fueron $3,81 \mathrm{~mm}, 2,36 \mathrm{~mm}$ y $3,50 \mathrm{~mm}$, respectivamente. El núcleo prominente olivar, el tracto piramidal y el núcleo vestibular fueron indicativos de una buena coordinación motora y equilibrio, mientras que el escaso desarrollo de los puntos del núcleo del tracto solitario indican una menor eficiencia de las funciones autonómicas en este roedor. El presente estudio servirá para conducir futuros estudios sobre el neuro-comportamiento necesario para una efectiva domesticación y adaptación de la rata gigante de carillos africana adulta.

PALABRAS CLAVE: Núcleos de los nervios craneales; Núcleos de los nervios no craneales; Bulbo raquídeo; Obex.

\section{REFERENCES}

Adogwa, O. A.; Lakshminarasimhan, A. \& Ghaji, A. The nuclei configuration of the one-humped camel. Zariya Vet., 5:16-27, 1990.

Allen, G. V. \& Cechetto, D. F. Functional and anatomical organization of cardiovascular pressor and depressor sites in the lateral hypothalamic area: I. Descending projections. J. Comp. Neurol., 315:313-32, 1992.

Ariens-Kapper, C. U.; Huber, G. C. \& Crosby, E. C. The comparative anatomy of the nervous system of vertebrates including man. New York, Hafner Publishing Company, 1960.

Arora, L. \& Prakash, R. Animal studies: Cytomorphometry of hypoglossal nucleus in rats. Indian Journal for the Practising Doctor, 3:11-2, 2006.
Bieger, D. \& Hopkins, D. A. Viscerotopic representation of the upper alimentary tract in the medulla oblongata in the rat: The nucleus ambiguus. J. Comp. Neurol., 262:546-62, 1987.

Breazile, J. E.; Jennings, D. P. \& Swafford, B. C. Conduction velocities in the corticospinal tract of the horse. Exp. Neurobiol., 17:357, 1967.

Carpenter, M. B. Core Text of Neuroanatomy. Baltimore, Williams and Wilkins, 1991. pp.115-7.

Drury, R. A. B. Carlton's histological technique. Ann. Intern. Med., 67:233, 1967.

Fiedler, L. A. Rodents as a food source. In: Vertebrate Pest Conference Proceedings Collection. Davis L. R. \& 
Marsh, R. E. (Eds). University of California Press, 1990. pp.149-55.

Guo, Y.; Goldberg, S. J. \& McClung, J. R. Compartmental organization of styloglossus and hyoglossus motoneurones in the hypoglossal nucleus of the rat. Brain Res., 728:277-80, 1996.

Hirano, A. \& Zimmerman, H. M. Silver impregnation of nerve cells and fibres in celloidin sections: A simple impregnation technique. Arch. Neurobiol., 6:114-22, 1962.

Ibe, C. S.; Onyeanusi, B. I.; Hambolu, J. O. \& Ayo, J. O. Sexual dimorphism in the whole brain and brainstem morphometry in the African giant pouched rat (Cricetomys gambianus, Waterhouse 1840). Folia Morphol., 69:69-74, 2010.

Jennings, D. P. Supraspinal control of posture and movement. In: Dukes' Physiology of Domestic Animals. Reece, W. O. (Ed.). Ithaca, Cornell University Press, 2004. pp.90420.

Kiernan, J. A. Histological and histochemical methods: theory and practice. Oxford, Pergamon Press, 1990. pp.320-44.

King, A. S. Physiological and Clinical Anatomy of the Domestic Mammals. London, Oxford University Press, 1993.

Krammer, E. B.; Rath, T. \& Lischka, F. M. Somatotopic organization of the hypoglossal nucleus: a HRP study in the rat. Brain Res., 170:533-7, 1979.

Lue, J. H.; Jiang-Shieh, Y. F.; Shieh, J. Y. \& Wen, C. Y. The synaptic interrelationships between primary afferent terminals, cuneothalamic relay neurones and GABAimmunoreactive boutons in cuneate nucleus. J. Neurosci. Res., 24:363-71, 1996.

Lue, J. H.; Shieh, J. Y.; Chen, K. N. \& Wen, C. Y. Synaptic relationships between GABA-immunoreactive boutons and primary afferent terminals in the rat cuneate nucleus. Neuroscience, 56:973-9, 1993.

Majewska-Michaska, E. Vascularization of the brain in guinea pig III. Vascular architecture of the medulla oblongata, pons, and cerebellum. Folia Morphol., 56:416, 1997.

Noback, C. R. \& Gross, L. Brain of gorilla: surface anatomy and cranial nerve nuclei. J. Comp. Neurol., 3:321-44, 1959.

Nolte, J. The Human Brain: An Introduction to its Functional Anatomy. St. Louis, Mosby, 2002. pp.262-90.

Nomina Anatomica Veterinaria. International Committee on Veterinary Gross Anatomical Nomenclature. $5^{\text {th }}$ Ed. Hannover, Germany, 2005.

Paxinos, G. The Rat Nervous System. Oxford, Elsevier Academic Press, 2004. p.315.

Paxinos, G. \& Watson, C. The Rat Brain in Stereotaxic Coordinates. New York, Academic Press, 1998. pp.811.

Ramaswamy, S. Removal of the brain - A new procedure. Ital. J. Anat. Embryol., 82:105-10, 1978.

Sricharoenvej, S.; Niyomchan, A.; Lanlua, P.; Piyawinijwong, S. \& Roongruangchai, J. Microvasculature of the medulla oblongata in the Lyle's flying fox (Pteropus lylei). Anat. Histol. Embryol., 37:401-7, 2008.

Sturrock, R. R. Loss of neurones from the cuneate nucleus lateralis of the ageing mouse brain. J. Anat., 163:13541, 1989.

Welker, W.; Johnson, J. I. \& Noe, A. Major national resources for the study of brain anatomy. University of Wisconsin, Michigan State University and the National Museum of Health and Medicine, 1998. Available in: http://brainmuseum.org.

Correspondence to:

Dr. Chikera Samuel Ibe

Department of Veterinary Anatomy

Ahmadu Bello University

Zaria

Nigeria

Phone: +2348032882105

Email: writechikera@yahoo.com

Received: 24-08-2010

Accepted: 12-02-2011 